\title{
Box of bones 'clinches' identity of Piltdown palaeontology hoaxer
}

London. A trunk discovered under the roof of London's Natural History Museum appears to have provided vital evidence allowing the Piltdown fraud - one of the most successful hoaxes in scientific history - finally to be put to rest.

The canvas travelling trunk is marked with the initials of Martin A. C. Hinton, a curator of zoology at the museum at the time of the fraud. It contains bones stained and carved in the same way as the Piltdown fossils and associated artefacts.

The discovery is the first solid evidence in the case after decades of speculation. As Brian Gardiner, professor of palaeontology at King's College, London, is due to announce in his presidential address to the Linnean Society in London tomorrow (24 May), it appears to identify Hinton unequivocally as the hoaxer.

The story of what was to turn into the longest-running parlour game in the history of palaeoanthropology began in 1912 when Charles Dawson, a lawyer and antiquary, unearthed human skull and jaw fragments and primitive artefacts at a gravel pit at Piltdown, Sussex, in the south of England.

The find caused a sensation. The Piltdown skull seemed remarkably advanced, given the great age indicated by the bones of archaic forms of fossil mammal characteristic of Pliocene deposits. But the jaw seemed very primitive, and almost ape-like. Both tied in with the prevailing views of human ancestry, namely that humanity was the culmination of a very ancient lineage, and that the first modern human feature to emerge was the enlarged brain.

Several people immediately suspected fraud. But many considered the skull to be an immensely important find, in particular Arthur Smith Woodward, keeper of palaeontology at the museum.

Subsequent research showed humanity evolved quite differently. The human lineage turns out to be relatively young, and expansion of the brain took place relatively late in human history. Piltdown Man was increasingly seen as an aberrant offshoot.

Nevertheless, Smith Woodward remained convinced of the authenticity of the skull until the day he died; his book The Earliest Englishman, published in 1948, was dictated on his deathbed. But just five years later, chemical analyses by Kenneth P. Oakley of the museum showed that all the artefacts were of recent date. The skull came from a modern human, the jaw from an orang-utan.

The accompanying mammal fossils, it emerged, had been 'planted' to give the human fossils an authentic context. All the objects had been carefully stained and abraded to appear old. Artefacts such as a piece of elephant bone carved to look like a cricket bat (a fitting accoutrement
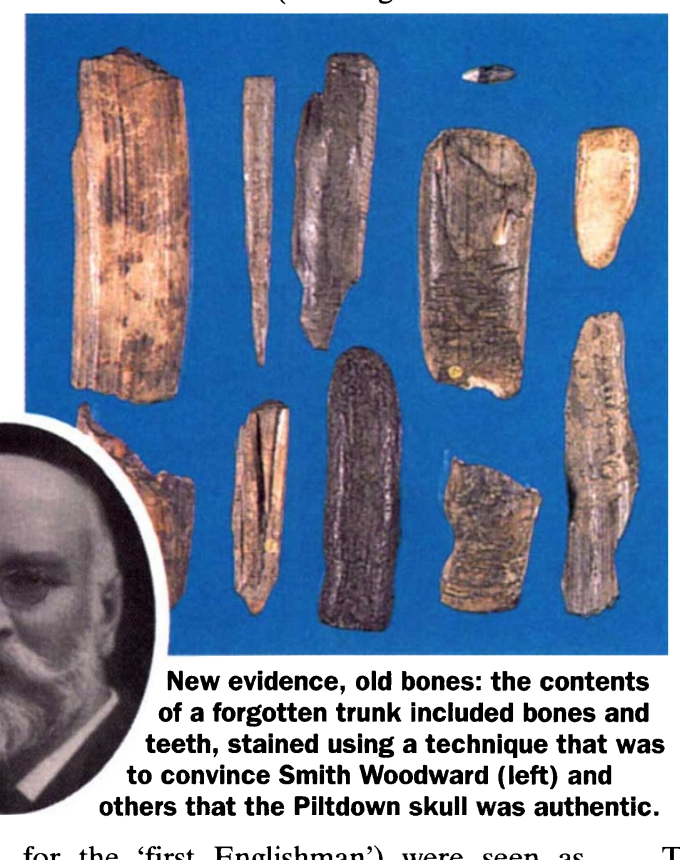

for the 'first Englishman') were seen as part of an elaborate joke. But who was the joker, and why?

Dawson was the prime suspect. But as he died in 1916, he could hardly be confronted with the evidence. Indeed, since 1953, virtually everyone connected with Piltdown Man has come under suspicion as the hoaxer, from the distinguished anatomists Arthur Keith and Grafton Elliot Smith to Teilhard de Chardin, the palaeontologist priest, and even Sir Arthur Conan Doyle, the creator of Sherlock Holmes, who lived nearby and is known to have visited the site.

Hinton has not escaped previous suspicion. Writing in The Common but Less Frequent Loon and Other Essays, published this year, Keith S. Thomson suggested that Dawson initially perpetrated the fraud, but that it was immediately spotted by Hinton. But Thomson claimed that because Hinton was afraid of exposing his boss, Smith Woodward, to ridicule, he sought to expose the hoax by planting increasingly ridiculous fossils, such as the 'cricket bat', at the site in order to scare Dawson and expose him as a fraud in the eyes of Smith Woodward.

But the new evidence contained in Hin- ton's trunk disproves this scenario. It now turns out that all the Piltdown remains were stained with the same chemical recipe, one that was invented by Hinton. The evidence appears to identify Hinton as the sole fraudster - and Dawson as his unwitting dupe.

The trunk came to light in the mid-1970s, when contractors were clearing the loft space in the southwest tower of the museum before maintenance work was carried out on the roof. It came to the notice of Andrew Currant, a researcher at the museum specializing, as did Hinton, in fossil rodents.

The trunk contained hundreds of vials of rodent dissections - described by Currant as "quite macabre". But at the bottom lay a hidden treasure: a collection of carved and stained pieces of fossil hippopotamus and elephant teeth, as well as assorted bones, that looked as if they belonged in the Piltdown collection.

Realizing the potential importance of what could be the 'smoking gun' to one of the great hoaxes of the century, Currant mentioned the existence of the trunk to Gardiner, who had been on the Piltdown trail since the hoax was first exposed in 1953, and was already certain from circumstantial evidence that it led to Hinton's door.

The trunk was the final piece of the puzzle - and the clinching solid evidence that Gardiner needed to establish his case. $\mathrm{He}$ and Currant have spent the last few years studying its contents and reanalysing the Piltdown collection. As Gardiner is due to announce to the Linnean Society tomorrow, they are now certain that Hinton was the sole author of the fraud.

Hinton himself, who published widely on many aspects of zoology and palaeontology, was something of a prodigy. In 1899, at the age of sixteen, he published a paper showing how fossils in river gravels would be impregnated with oxides of iron and manganese, staining them a characteristic chocolatebrown colour.

Oakley's analyses showed that the Piltdown fossils were enriched in iron, as one would expect if they were genuinely old even though their recent age was indicated by other factors. But Oakley did not look for manganese. Crucially, analyses of the contents of Hinton's trunk by Currant and Gardiner show that they are enriched in iron as well as manganese - in the same proportions as in the Piltdown specimens.

The Piltdown fossils - with one 
- important exception - as well as the contents of Hinton's trunk, are also enriched with chromium. This appears to have been a result of the staining process.

Before staining, Hinton would have used chromic acid as an ingredient in a recipe to turn the apatite (the mineral component of bone) to gypsum. This process would have etched the bone surface, making it easier for the manganese and iron oxides to penetrate the specimens. But traces of chromium would remain.

The one exception was the orang-utan jaw. This could not be etched because it contained two teeth, and acid-etching of the teeth would have been a clear sign of a forger at work. Hinton was therefore careful not to treat these in the same way. The teeth were lightly stained so as not to risk etching, and an isolated canine tooth was painted further with paint (possibly burnt umber) rich in manganese and iron.

Gardiner and Currant's suspicions about Hinton's difficulties with teeth received support in 1991 after Gardiner contacted Robert J. G. Savage, then professor of geology at the University of Bristol, telling him of Currant's discovery of the Hinton trunk. Savage had been the executor of Hinton's estate - a considerable task, given that Hinton was a lifelong hoarder.

Savage sent Gardiner some glass tubes from Hinton's hoard. These contained eight human teeth that had been stained in various ways. The teeth, together with the con- tents of the trunk, reveal a forger testing out his methods. The staining recipe of iron, manganese and chromium seems to have been Hinton's own, based on his knowledge of post-depositional processes affecting fossils in gravel.

Why the Piltdown gravels? Hinton was an expert on the geology of the Weald area of Sussex, in which Piltdown is located: Gardiner and Currant believe Hinton chose the Piltdown gravels precisely because they were entirely unfossiliferous, leaving Hinton a clear field Hinton (centre) at work in the Natural History Museum. to execute the fraud. Dawson and, through him, Smith Woodward, was led to the scene - and the rest is history.

Hinton knew Dawson was an incompetent geologist and would serve as the dupe; Dawson had already unknowingly traded a stone implement, stained to look old by Hinton, with Harry Morris, an expert on stone tools. This later turned up in Morris's collection labelled that it had been stained by Dawson with intent to defraud. Gardiner argues that Dawson is unlikely to have traded a flint he had faked with an expert such as Morris if he had he done it himself.

The real victim seems to have been Smith Woodward, and the motive an argument about money. In 1910, Hinton wrote to Smith Woodward asking for vacation

\section{Basic research wins out in UK spending}

London. Policy changes introduced by the British government over the past ten years have resulted in a major shift in the balance of public spending on research and development (R\&D), according to figures released by the government this week as part of its annual Forward Look.

In particular, basic research has increased its total share of such spending from 19.1 per cent in 1985-86 to 33.3 per cent in 1994-95. In contrast, government spending on 'experimental development' has fallen from 44.2 to 28.9 per cent of its total $R \& D$ expenditure, in line with its commitment to pass responsibility for such investment to the private sector.

Largely as a result of an accelerated shift in this latter direction, overall spending by the British government on civilian research and development, after a spurt at the beginning of the decade, has slowed down again. The figures published this week show that total expenditure on civilian $R \& D$ increased last year by only 1.4 per cent in cash terms - to a total of $£ 3.17$ billion (US $\$ 4.79$ million) - compared to a 4.4. per cent increase the previous year.
A major drop in spending on military research in particular has meant that the government's total R\&D budget fell in cash terms for the first time for more than a decade. But spending on the science and engineering base - including the seven research councils - grew by 4.1 per cent, slightly higher than inflation. Basic research has increased its share of the civilian R\&D budget from 35.1 per cent in $1985-86$ to 54.9 per cent last year.

In terms of public spending on R\&D by socio-economic objectives, the proportion spent on health has increased from 4.5 to 7.6 per cent between 1986-87 and 1994-95, and on environmental protection from 1.1 to 2.3 per cent. In contrast, spending on new energy sources has seen its share of the total fall from 4.4 to 1.1 per cent.

Sir Robert May, head of the Office of Science and Technology and the government's chief scientific adviser, says that a special effort has been made to make the report, which is intended to provide the government with an annual transdepartmental 'snapshot' of science spending, more readable than in the previous two years.

\section{IMAGE UNAVAILABLE FOR COPYRIGHT REASONS}

employment cataloguing rodent remains at the museum. Woodward agreed, provided the payment of $£ 130$ was made after completion of the work, as was customary.

Hinton responded with a letter requesting that the sum be paid as a weekly wage, and detailing elaborate and costly plans for a catalogue. Woodward's reply, if any, does not survive, but as a senior figure (and experienced cataloguer) he is unlikely to have been impressed by the presumption of a junior colleague.

Whatever the outcome of the dispute, Hinton spent most of his subsequent career in the zoology department of the museum, away from Woodward's palaeontology department - even though much of Hinton's work concerned fossils.

Although the evidence of Hinton's responsibility appears strong, some doubts will inevitably remain among those who have studied the case closely. "It's a very convincing link between Piltdown and Hinton," says Chris Stringer, a palaeoanthropologist at the Natural History Museum. "But I still have my suspicions that Dawson was involved."

But Gardiner feels that the evidence for Hinton having been the sole hoaxer is now conclusive. He points out, for example, that Hinton was well-known for his elaborate practical jokes. The Piltdown fraud would have been an ideal way to get back at the pompous, stuffy keeper of palaeontology. Such suspicions are strengthened by the text of a letter Hinton wrote in 1954 to the evolutionary biologist Gavin de Beer - then the director of the British Museum (Natural History), now the Natural History Museum - after the fraud had been exposed.

"The temptation to invent such a discovery of an ape-like man associated with late Pliocene mammals in a Wealden gravel might well have proved irresistible to some unbalanced member of old Ben Harrison's circle at Ightham," wrote Hinton, a reference to his circle of Sussex-based geologist colleagues. "He [Harrison] and his friends [of whom Hinton was one] were always talking of the possibility of finding a late Pliocene deposit in the Weald." Given what we now know, this reads as almost a signed confession.

Henry Gee 